\title{
CULTIVATING CRITICAL THINKING ABILITY IN BTI IN CHINA
}

\author{
Yuehong Wei \\ English Department, North China Electric Power University, Baoding, Hebei, China \\ E-mail:wyh231@163.com
}

APA Citation: Wei, Y. (2018). Cultivating critical thinking ability in BTI in China. Indonesian EFL Journal, 4(2), 90-98. doi: 10.25134/ieflj.v4i2.1380.

Received: 28-03-2018

Accepted: 29-05-2018

Published: 01-07-2018

\begin{abstract}
It is very vital for students in BTI to grasp the critical thinking ability, but how to cultivate this ability in the fundamental courses is a big problem to be solved. This study is to employ the teamwork, such as group discussion and group representation, and reflection log in the teaching process, investigating the dynamic situation through questionnaires. The results showed that group discussion, group presentation and reflection log are the effective ways to promote students' critical thinking skills; however it cannot improve the critical thinking promptly in such a short time and it will be a successive process. Therefore, carrying out some class activities can enhance students' critical thinking skills in English reading class.
\end{abstract}

Keywords: BTI, English reading, critical thinking, teamwork, reflection log

\section{INTRODUCTION}

The recent years have seen the rapid development of BTI in China and scholars have attached increased importance to the cultivation of critical thinking in the stage of accumulating fundamental knowledge (Lei, 2015; Tao \& Xiao, 2015). In western education, critical thinking has caught wide attention (Bailin \& Siegel, 2003; Tsui, 2002; Moon, 2008) and has become the main educational objectives through elementary education even to university education. In China, the critical thinking cultivation, especially of undergraduate, has roused much attention of many scholars (Liu, 2013; Sun, 2013; Ren, 2013; Lin, 2014; Wen, 2014) focusing on research on combining critical thinking with language ability development. Meanwhile, some scholars pointed out that the critical thinking of students majored in foreign languages needs to be developed.

Cultivating critical thinking ability is the important part of enhancing the translation ability (Zhong, 2013; Miao, 2007). Through researches for many years, Miao (2007) further proposed that translation ability not only involves bilingual competence, transfer competence and world/subject knowledge, but also other competence, which refers to applying strategies to solve problems and displaying mental quality and skills. The transfer competence and the strategies of solving problems are tightly related to analysis of critical thinking competence and problemsolving competence. The effect of mental quality and skills are consistent with the personality trend in critical thinking competence. We can find out that in the stage of fundamental course of BTI, we should not only cultivate students' language knowledge but also strengthen their critical thinking competence.

Domestic researches on critical thinking are on the increase day by day. Though domestic scholars have different explanations about the definition of critical thinking competence, yet most researches adopt the term "critical thinking competence" suggested 
Yuehong Wei

Cultivating critical thinking ability in BTI in China

by Wen (2009). It means that students should have various thinking competence such as analysis and synthesis, abstract and generalization, analyzing problems from many perspectives and innovation competence such as finding problems and solving problems.

Elder and Paul (2005) argued that critical thinking should be defined as applying appropriate evaluation standard and conscious thinking to decide the true value of something and finally making a reasonable judgment. It includes three dimensions: analysis, evaluation and improvement (Wen, 2008). At abroad, the statement which has influence on critical thinking competence is the twodimensional critical thinking competence model in American Delphic program and three-dimensional critical thinking competence model of Elder and Paul (2005). In China, Wen (2013) constructed the theoretical model of critical thinking competence level and triangular structure model of psychological. However, critical thinking competence level theory is different from other three models. It includes metacritical thinking competence and critical thinking competence, which emphasizes on distinguishing self-regulation competence from general critical thinking competence. It is higher than general critical thinking competence, which means the skills of examining, regulating and evaluating one's critical thinking plan. The critical thinking competence we refer to is the first-level competence, which includes skills and standard of critical thinking and emotional qualities displaying personality trend. Its cognitive skills include three core aspects, which are analysis, inference and evaluation. The cognitive standards include clarity, relevance, logic, profundity and flexibility. The emotional dimension in the model includes five emotional characters which are curiosity, open, confidence, integrity and firm (Wen, 2013). This theory model materializes the abstract critical thinking competence, making the cultivation of critical thinking more manipulative and standardized.

The critical thinking competence involves independent consideration, verifying spirit and innovation spirit as well as general mental competence such as analysis, contrast, synthesis, inference, speculation, examination and evaluation. Cognitive scientists proposed that reading comprehension is a complex cognitive process (Anderson \& Pearson, 1984; Afflerbach, 1990; Green, 2005). Yang (2015) pointed out that the cognitive character and critical thinking competence of reading comprehension should be of highly coincidence. If teaching reading involves the guidance and examination in aspects of interpretation, analysis, evaluation, reasoning and explanation for students, then it involves the cultivation on critical thinking competence.

The purpose of cultivating critical thinking competence in the reading course of BTI is to help students set foundation of enhancing translation competence. Translation is a complex process of language conversion. It not only contains language code conversion, but also the decision-making process of translator in language conversion. Therefore, cultivating the critical thinking competence of students of BTI is the presupposition of promoting translation competence. The autonomous university of Barcelona in Spain has put forward the model of translation capability in terms of translation capacity project. It is constructed by a series of related, hierarchical, changeable components including communicative ability, non-verbal ability, psycho-physiological factors, professional operation ability, transformational ability and strategic ability.

In 2003, translation competence is further defined as communicative ability, non-verbal ability, transfer ability, psycho-physiological factors, professional operation ability, and strategic ability. Among them, strategic ability is the operation knowledge which guarantees the efficiency of translation and solves the 
appeared problems. Strategic ability is of great importance in that it controls the translation process, effects other translation competence and coordinate the relationship among them to fill the gap. It can also solve problems once it discovers them. So, in the stage of fundamental knowledge, we could meet the demand of competence cultivation on the senior students of BTI through reading course, laying a foundation for translation competence of BTI. In other words, in the stage of basic knowledge cultivation, we should not only put emphasis on the cultivation of applying language knowledge but also on the skills like analysis, contrast, synthesis, inference, speculation, examination and evaluation and the cultivation on emotional character of personality trend.

Having those backgrounds, this study aims to cultivate the critical thinking competence of BTI in reading class as its medium and lay a foundation for the study of advanced translation courses. The specific research questions are as follows:

1) What are effective ways of cultivating critical thinking competence of students of BTI in English reading course?

2) What's the trend of students' critical thinking competence of English reading course?

3) What are the problems in the development process of students' critical thinking competence in reading feedback?

\section{METHOD}

Taking the students of one class majored in BTI as research object, this study conducted the survey lasting three semesters. This class has 26 students including 4 boys and 22 girls. These 26 students come from 24 different provinces across the country with ages from 16 to 18 years old. About $50 \%$ of the students in this class are willing to be majored in translation and $25 \%$ of the students follow others' advice. Others were adjusted to this major. This study adopts some data collection techniques including questionnaire, reflection log, group cooperation, wheel display, and class report.

In this study, the reading courses were chosen for the two semesters of fresh year and the first semester of sophomore year, which are the main content of this research. In the fourth semester, mock exam is arranged for TEM4, so it is not suitable for this teaching research. In these three semesters, the learning plan and time schedule are introduced for students at the beginning of each semester. The content of textbook runs through the whole semester and special reading activities are held in stages.

In the first semester, two questionnaires are made at the beginning and the last. The first questionnaire aims to make a survey of students' reading experience before and the last questionnaire aims to make a survey of critical thinking process of students' feedback for class and reading. Besides regular textbook, this semester includes three "special reading activities": choosing The Old Man and the Sea, newspapers and magazines of foreign language and short novel in English selected by students themselves. Each activity are completed in three weeks with 6 periods. The first two thematic activities involve a group discussion and a group report. The content of discussion consists of problems, difficult points and analysis of language styles that need to be concerned in reading. The content of report consists of the cultural background of reading materials, the solution of difficulties in reading, accumulation of language knowledge and enlightenment of real life. The third one is completed independently by students based on the first two theme and students should submit a written reading report. In every week, students are required to submit the reflection logs according to their own reading condition.

In the second semester, the reading content is added with series of newspapers and extracurricular autonomous reading. Report 
Yuehong Wei

Cultivating critical thinking ability in BTI in China

form is changed from reading feelings into scenarios show. Newspaper reading and textbook learning run through the whole semester and after-class learning is combined with class discussion according to teaching schedule. Another two reading thematic activities are held, which refer to the reading of English original novel Far From the Madding Crowd and the Shakespeare Tales. In this semester, reflection logs are demanded to submit after thematic activities and meanwhile reflect on thematic activities and daily reading activities.

In the third semester, the theme of newspaper reading and textbook learning run through the whole semester. The group of two persons should complete independently three task presentations including background knowledge, language knowledge and putting forward questions of reading comprehension. Reading theme refers to reading English original novels and having group discussion in reading process. The main content of discussion is to comb the details of the novel and discuss the author's intention and the effect of language based on it. This semester has added reading materials of the discussion activities and designed the reading teaching materials in groups

\section{RESULTS AND DISCUSSION Analysis of statistical results of questionnaire survey}

From the first eight questions in the first questionnaire survey, it was found that the students' English reading habits in high school: $85 \%$ of the students chose "never" or "sometimes" reading English books and two of the students chose "often" reading English newspapers. English newspapers mainly refers to the high school English learning newspaper, while only $15 \%$ of the students chose "often" or "always" reading English books. But 100 percent of students chose "often" or "always" in the title of in high school learning, English reading mainly refers to exercises reading.

The result suggests that students have a narrower range of English reading, which is an obvious deficiency in the cultivation of BTI students. Therefore, in English reading course of fundamental course stage, we should expand students' reading range and develop good reading habit, separating appropriately reading from reading comprehension for exam. After finishing class activities and questionnaire, we found out that class reading helped a lot for forming right reading habit of students and efficient group activities will promote students' reading interest and result. Students come to know the native English expression and writing character of newspaper report by reading newspapers and magazines. And the translation practice accompanied by reading has also laid the foundation for the translation of political subjects.

In this study, the questionnaire data was gathered in Excel, and the change analysis chart was drawn. Figure 1 shows a comparison of the statistics of 26 students in the three questionnaires. Figure 2 shows the trend of each questions' change in the three questionnaires' results. The final examination results of students in three semesters were collected as the reference data to find out whether reading ability is related to critical thinking competence. Final exam papers contain 50\% reading ability and 50\% basic words and grammar. Since the basic vocabulary and grammar are the foundation of reading ability, then the final result can reflect the students' reading ability. 


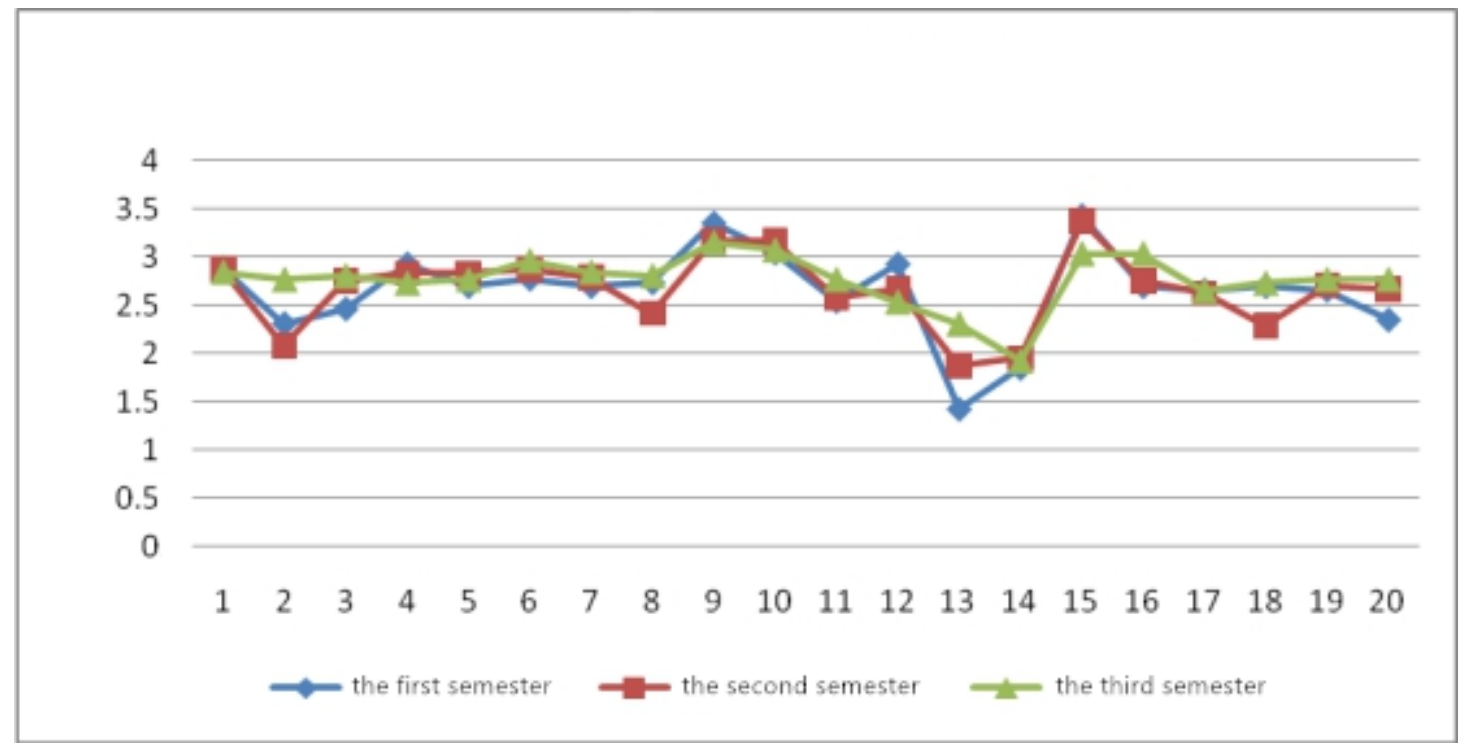

Figure 1. Students'learning attitude

To analyze the correlation of the results of grade average point in the three semesters and questionnaire results, Pearson correlation inspection was conducted to get the data: correlation coefficient $r$ of $0.202,|| r<0.3$, suggesting that relationship between two variables is very weak so there is no correlation. In addition, the $\mathrm{p}$ value was 0.3445 and the $p$ value was much higher than the average confidence level 0.05 . The results of the analysis showed no correlation between the reading grade and the mean of the questionnaire survey. Students' critical thinking ability and reading ability displayed in scores of reading class have no correlation. For example, some students have high reading scores, but not necessarily have good critical thinking ability. Some students have low reading scores, but have relatively strong critical thinking ability. The problem is that their language comprehension is not high, so they should increase their vocabulary mastery, become familiar with grammar knowledge and increase their reading quantity.

The comparison between Table 1 and Figure 2 shows that the results of reading courses are not completely relevant to the investigation of critical thinking competence. In Table 1, the lowest points are: 60 in the first semester, 69 in the second semester, and 67 in the third semester. Moreover, the highest points are 89 in the first semester, 91 in the second semester, and 95 in the third semester. Seen from the highest points, the trend and grade are positively correlated. In other words, for students doing well in study, critical thinking ability and reading scores have certain correlation.

Table 1. The average score of three semesters

\begin{tabular}{cccccccc}
\hline $\begin{array}{c}\text { Std. } \\
\text { No. }\end{array}$ & $\mathbf{1}^{\text {st }}$ semester & $\mathbf{2}^{\text {nd }}$ semester & $\mathbf{3}^{\text {rd }}$ semester & $\begin{array}{l}\text { Std. } \\
\text { No. }\end{array}$ & $\mathbf{1}^{\text {st }}$ semester & $\mathbf{2}^{\text {nd }}$ semester & $\mathbf{3}^{\text {rd }}$ semester \\
\hline $\mathbf{1}$ & 60 & 70 & 67 & $\mathbf{1 4}$ & 67 & 82 & 90 \\
$\mathbf{2}$ & 70 & 82 & 93 & $\mathbf{1 5}$ & 60 & 69 & 84 \\
$\mathbf{3}$ & 71 & 78 & 94 & $\mathbf{1 6}$ & 76 & 88 & 95 \\
$\mathbf{4}$ & 62 & 71 & 71 & $\mathbf{1 7}$ & 79 & 81 & 94 \\
$\mathbf{5}$ & 70 & 87 & 94 & $\mathbf{1 8}$ & 71 & 69 & 77 \\
$\mathbf{6}$ & 73 & 79 & 92 & $\mathbf{1 9}$ & 84 & 90 & 94 \\
$\mathbf{7}$ & 70 & 79 & 93 & $\mathbf{2 0}$ & 75 & 87 & 93 \\
\hline
\end{tabular}


Yuehong Wei

Cultivating critical thinking ability in BTI in China

\begin{tabular}{cccccccc}
\hline $\mathbf{8}$ & 84 & 84 & 94 & $\mathbf{2 1}$ & 75 & 76 & 91 \\
$\mathbf{9}$ & 82 & 91 & 97 & $\mathbf{2 2}$ & 67 & 78 & 89 \\
$\mathbf{1 0}$ & 60 & 73 & 86 & $\mathbf{2 3}$ & 67 & 80 & 88 \\
$\mathbf{1 1}$ & 87 & 91 & 95 & $\mathbf{2 4}$ & 60 & 71 & 91 \\
$\mathbf{1 2}$ & 76 & 75 & 91 & $\mathbf{2 5}$ & 89 & 85 & 92 \\
$\mathbf{1 3}$ & 80 & 83 & 91 & $\mathbf{2 6}$ & 68 & 76 & 87 \\
\hline
\end{tabular}

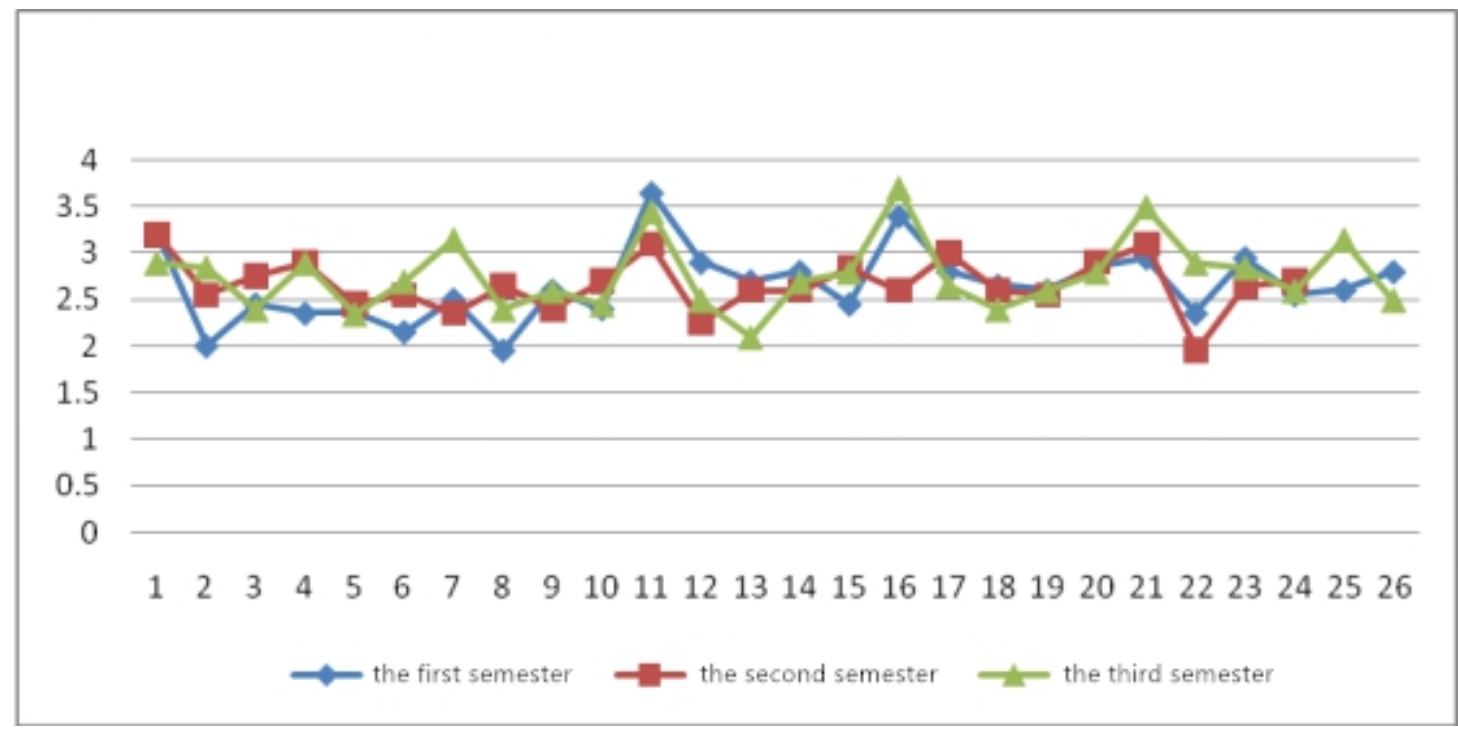

Figure 2. The tendency of each item in questionnaire

The change trend in Figure 2 shows that the survey results in the third semester basically showed a steady trend, but the changes of the three semesters did not change significantly. Questions 2, 13, 18, 20 have obvious changes. The third term is superior to the former two semesters and the results are closely related with three semesters of teaching contents and teaching forms. In this semester, reading activities are carried out including English newspaper reading and collecting the materials of reading background. Question 3, 6, 7, 8, 11, 17 and 19 are steadily rising and the part can reflect that learners have promoted preliminary critical thinking ability. The change is the result of carrying out activities such as group activities in class, reading skills training and communication of reader response.

\section{Analysis of reflection logs}

Reflection logs have been acknowledged by most students. In this process, students can analyze and explain their reading course. They can find the problems and then solve them so as to assess and improve themselves. Analyzing one's learning condition is the beginning of cultivating analysis competence. Try to find solutions to problems after clarifying them. This point has been indicated in reflection logs. Some students reflect on the progress of reading and remind themselves of their constant adjustments; Some students reflect on the harvest in group activities and find their own shortcomings and correct them in later reading activities; Some students write specific reading skills and language knowledge in the reflection log, which can strengthen the memory and highlight the key of learning; Some students reflect on the thinking process of reading, including the approbation and disapprobation of the content of the novel, and state reasons; Some students reflect on their emotional changes when they read a novel, resonating with the author or becoming curious about something mentioned 
in the novel, which stimulate their own reading interest; However, some students think that reflection log is a mission, holding a view that reading class highlights reading instead of reflection. It makes sense to some extent, but if we just take reading as an understanding of characters, not considering the aim of reading and the effect of reading, it will definitely effect the cultivation of translators' critical thinking competence. It just as the translation emphasizes the meaning of the word, regardless of the context, even the cultural background and other related factors.

\section{Analysis of group activities}

Group activities are divided into group discussions and group reports. Reading report was carried out in the form of group report, which contains two types: Five-person group report and two-person group report. Fiveperson group report was carried out in first and second semester to promote communication and writing among students. Group activity is an efficient way of enhancing students' critical thinking competence. Most students in the reflection log reported that, in the group discussion, the communication with the other students opened their own thinking space and made them reflect on their own reading habits and ways of thinking. In the third semester, with reinforcement of students' self-study ability, two-person group report was carried out. It was more difficult in that it contained selected report of knowledge and put forward the questions in reading materials. Then, the questions would be organized to be discussed. This part was a challenge for students. Some students failed to analyze deeply the article and just lingered on the knowledge points and characters, while other students were able to propose some extended and profound questions. In addition, many students could not discuss focusing on the main topic. The reason lies in that the individual knowledge accumulation is limited, so increasing reading quantity should be the prerequisite of enhancing critical thinking competence.

There also exist problems in the process of group report. In the first semester, group members will show their PPT after finishing it. In the class, the group members focused on the task of the group, and were indifferent to the report of other groups, so they were unable to achieve the purpose of communication learning. One of the reasons is the difference between group reading materials. Also, teacher did not raise a specific claim of paying attention to other groups' report and the group reports are not so much attractive. Therefore, the form of group report was changed in the later two semesters.

In the three semesters of teaching experiment, sufficient group discussions were carried out in class. Firstly, in the study of textbook reading, students discussed about organized structure of articles in reading discussion and analyzed sentence hierarchy relation. They agreed that this kind of form is very beneficial for them. In this activity, students could understand article structure without the form of preparing for an exam, which embodies the basic competence of students who will be a translator in the future.

Secondly, in the form of wheel-type group discussion, each group should prepare their own computer and watch in turn and evaluate other groups' report. Each member in the group should seriously think about it and put forward questions. They should also take their group report into consideration and the real effect was good. The disadvantage of original groups' low participation has disappeared. This form develops students' competence of interpretation, analysis, comparison and evaluation, which strengthen students' curiosity in reading content.

Though group discussion in some extent enhances the analysis competence of students, yet they fail to know how to analyze in the process of it. When showing in wheel type, 
Yuehong Wei

Cultivating critical thinking ability in BTI in China

they cannot give a deep evaluation after group discussion but stay in the surface of questions. The reason is that the students' knowledge is limited and they cannot form comparative inference and judgment. So, a rich fund of knowledge must be precondition of the cultivation on the competence of critical thinking.

In the competitive group activity of asking words, students tend to prefer the objective form of activities. The process does not demand consideration but testing memory effect. So, the cultivation of critical thinking competence also needs teachers' positive orientation and encouragement. It is necessary to carry out efficient class activities.

In group activities, teacher's evaluation is combined with group members. Teacher appraises each group and evaluate performances of each student according to the teacher's evaluation form. This form can direct students to carry out group activities fluently and serves as a standard which student should follow in reading activities and group discussion. It is conducive to the development of classroom activities and the cultivation of integrity and self-confidence.

In this research, reflection log, group report and group discussion are effective ways to achieve the improvement of thinking skills, meet the thinking standard and cultivate the positive personality tendency.

\section{CONCLUSION}

This research took a long time, permeating the spirit of cultivating critical thinking competence in every class activity. The cultivation of ability is not achieved overnight, so we adopted a quiet way to make the students gradually form the competence of analysis, comparison, comprehension, reasoning, conjecture, inspection, evaluation, and cultivate positive personality tendency. Critical thinking competence is invisible, which is a form of cognitive ability. Though many scholars designed many measuring tools in an attempt to present objectively, which is a good try as well as a research direction, yet in actual teaching, especially in the competence cultivation of BTI, learners' critical thinking competence probably won't emerge as soon as learning finishes. It might require a lot of translation practices. By combining theory with practice, the effect of cultivating critical thinking competence will be displayed in translation practices.

This research is devoted to developing the critical thinking competence of BTI by means of reading class, thus laying the basis for senior translation course. Such group activities as group discussion, group reports and reflection logs are proved to be effective ways of cultivating critical thinking competence of BTI in English reading course. In these activities, students can learn to think, analyze, reason, judge and evaluate in their pre-reading, while-reading and post-reading activities. English reading course has a positive effect on fostering critical thinking competence. It is an abstract notion and an intellectual activity in the brain. It cannot be objectively detected. However, the present research aims to specifically foster abilities and the results reveal that reading process can improve critical thinking competence, which is a slow and gradual process and is implicit in a short time. The research also finds that the reading effects reflected in the improving process of students' critical thinking competence is not always linear but fluctuated with a positive general tendency. Therefore, to some extent, to carry out classroom activities consciously in reading course can improve students' critical thinking competence.

Yet, there are also some shortcomings in this study. As a concrete process, teachers work out the structure of development of critical thinking competence, but some students are unable to really think critically. For example, the questions and evaluations they issued are too superficial to present insightful suggestions on their reading 
Indonesian EFL Journal, Vol. 4(2) July 2018

p-ISSN 2252-7427, e-ISSN 2541-3635

contents; the questions they asked about other groups' reports are lack of logic. Meanwhile, their profound and logical standards in critical thinking should be improved. The researches in this field are hoped to continue in-depth studies and solve these problems.

\section{REFERENCES}

Bailin, S., \& Siegel, H. (2003). Critical thinking. In N. Blake, P. Smith, \& P. Standish (Eds). The blackwell guide to the philosophy of education (pp. 181-193). Oxford, UK: Blackwell.

Elder, L., \& Paul, R. (2005). Critical thinking: Learn the tools the best thinkers use. New Jersey: Pearson Prentice Hall.

Liu, X. (2013). On the construction of thinking ability training model in college English teaching. Foreign Language World, 3(5).

Miao, J. (2007). The study of translation competence: The basis of constructing translation teaching model. Foreign language and Foreign language Teaching, 7(4).

Sun, Y. (2013). Innovating the evaluation system of English specialty, leading the development of

\section{AISEE \\ The Asso ciation of Ind ones ian
Scholars of Engli sh Education}

students' speculative ability. Foreign Languages in China, 4(1).

Wen, Q. (2008). On the cultivation of high - level thinking ability of foreign language majors postgraduates. Academic Degrees and Graduate Education, 8(10).

Wen, Q. (2009). Constructing the theoretical framework of speculative measuring instruments for foreign language students in China. Foreign Language World, 9(1).

Wen, Q., Lingli, Z., \& Hao, S. (2014). Do foreign language majors have less speculative skills than other majors? Modern Foreign Languages, 4(6).

Wen, R. (2013). Rethinking about the ability of critical thinking of foreign language majors: "absent" or "presence"?--taking the English speech class as an example. Foreign Languages in China, 3(1).

Yang, L. (2015). Cognitive characteristics of questioning in reading classroom and cultivation of speculative ability. Foreign Languages in China, $5(2)$.

Zhong, W. (2013). Requirements for undergraduate teaching of translation major in colleges and universities. Chinese Translators Journal, 3(3). 